\title{
THE USE OF COMPUTER SIMULATIONS AS AN INTERVENTION TO ADDRESS MISCONCEPTIONS OF GRADE 11 PHYSICAL SCIENCES LEARNERS IN SOUTH AFRICAN TOWNSHIP SCHOOLS
}

\author{
James Mphafudi, \& Sam Ramaila \\ Department of Science and Technology Education, University of Johannesburg (South Africa)
}

\begin{abstract}
This study examined the affordances of the use of computer simulations as an intervention to address acid-base misconceptions of grade 11 Physical Sciences learners in South African township schools. Technological pedagogical content knowledge (TPACK) framework was invoked to provide valuable insights into the efficacy of computer simulations as an innovative intervention to address misconceptions associated with acids and bases. The study adopted a mixed-method approach located within a case study design and involved purposively selected grade 11 Physical Sciences learners from two South African township schools. Quantitative data was collected by administering Acids-Bases Chemistry Achievement Test developed by Damanhuri, Treagust, Won and Chandrasegaran (2016) as part of a control group-experimental group design. Qualitative data was collected through semi-structured interviews with the participants. Findings revealed significant differences between pre-test and post-test scores as a result of the implementation of virtual laboratory simulations as a remedial intervention. The results showed that the post-test mean score was significantly higher $(\mathrm{M}=38, \mathrm{SD}=14)$ than the pre-test mean score $(\mathrm{M}=26, \mathrm{SD}=10)$ for the experimental group. There was no significant difference between the post-test mean score $(M=32, S D=13)$ and the pre-test mean score $(M=30, S D=11)$ for the control group. Elicited responses indicated that learners perceived the use of virtual laboratory simulations as a useful alternative means to demystify abstract scientific concepts associated with acids and bases as a Physical Sciences key knowledge area. In addition, the learners demonstrated fundamental appreciation of the affordances of virtual laboratory simulations as an innovative intervention to address misconceptions. The use of virtual laboratory simulations was largely perceived to provide meaningful opportunities for self-directed learning. However, the learners indicated that virtual laboratory simulations cannot supersede the experiences provided by traditional science laboratories in view of their critical role in the development of science process skills. Theoretical implications for meaningful development of technology-enhanced learning are discussed.
\end{abstract}

Keywords: Misconceptions, virtual laboratory simulations, technology-enhanced learning.

\section{Introduction}

Inadequate performance of learners in Physical Sciences can partly be attributed to prevailing misconceptions associated with various content knowledge areas (Reddy, 2006). In particular, research has demonstrated that high school learners hold several misconceptions about acids and bases (Artdej, Ratanaroutai, Coll \& Thongpanchang, 2010). Lack of essential resources at township schools in South Africa renders meaningful enactment of contemporary pedagogic approaches such as inquiry-based learning a daunting task for teachers. The use of computer simulations can be a viable alternative mechanism for adequately addressing misconceptions associated with various Physical Sciences content knowledge areas. This study explored the efficacy of computer simulations as an intervention to address misconceptions associated with acids and bases with a view to enhance meaningful conceptual understanding.

\section{Research design and methodology}

This study adopted a mixed-method approach as part of a case study involving purposively selected grade 11 Physical Sciences learners from two South African township schools. The mixed-method approach is appropriate as it aims to draw on the strengths and reduce the weaknesses of the quantitative and qualitative methods (Johnson \& Onwuegbuzie, 2004). Quantitative data was collected by means of a validated instrument which was administered as part of control group-experimental group design. The validated instrument used for collection of quantitative data is 
Acids-Bases Chemistry Achievement Test developed by Damanhuri, Treagust, Won and Chandrasegaran (2016). Statistical Package for Social Sciences (SPSS) version 25 was used to analyse quantitative data. Qualitative data was collected through semi-structured interviews with the participants.

\section{Findings}

Quantitative data was collected by means of Acids-Bases Chemistry Achievement Test (ABCAT) developed by Damanhuri, Treagust, Won and Chandrasegaran (2016).

\subsection{Comparison of pre-test and post-test performances in the ABCAT}

Data was analysed to compare learners' understandings of acid-base concepts in the pre-test and post-test using the ABCAT. The control group was not exposed to the use of virtual laboratory simulations while the experimental group was exposed to the use of virtual laboratory simulations. The virtual laboratory simulations adopted for utilisation in this study were sourced from the Physics Education Technology (PhET) Research Project of the University of Colorado in the United States of America. Table 1 below depicts the performance of the control group in relation to the two sections constituting the questionnaire. There was no significant difference between the pre-test and post-test scores for both sections in relation to the control group.

Table 1. Pre-test and post-test scores for the control group $(N=27)$.

\begin{tabular}{|c|c|c|c|c|c|}
\hline \multirow[b]{2}{*}{ Section } & \multicolumn{2}{|c|}{ Pre-test } & \multicolumn{2}{|c|}{ Post-test } & \multirow{2}{*}{$\begin{array}{l}\text { Effect size } \\
\text { (Cohen's } d \text { ) }\end{array}$} \\
\hline & Mean & SD & Mean & SD & \\
\hline Section A & 2.9 & 1.1 & 3.1 & 1.3 & 0.32 \\
\hline Section B & 2.5 & 0.9 & 2.8 & 1.1 & 0.29 \\
\hline Total & 5.4 & 2.0 & 5.9 & 2.4 & 0.61 \\
\hline
\end{tabular}

**p $<0.01$ (Note: Section A consists of 10 multiple-choice items; Section B consists of nine two-tier multiple-choice items).

Table 2 below depicts the performance of the experimental group in relation to the two sections constituting the questionnaire. The post-test scores were significantly higher than the pre-test scores for both sections in relation to the experimental group.

Table 2. Pre-test and post-test scores for the experimental group $(N=26)$.

\begin{tabular}{|c|c|c|c|c|c|}
\hline \multirow[b]{2}{*}{ Section } & \multicolumn{2}{|c|}{ Pre-test } & \multicolumn{2}{|c|}{ Post-test } & \multirow{2}{*}{$\begin{array}{l}\text { Effect size } \\
(\text { Cohen's } d)\end{array}$} \\
\hline & Mean & SD & Mean & SD & \\
\hline Section A & 3.1 & 1.2 & 4.0 & 1.5 & 0.46 \\
\hline Section B & 2.1 & 0.8 & 3.7 & 1.4 & 0.43 \\
\hline Total & 5.2 & 2.0 & 7.7 & 2.9 & 0.89 \\
\hline
\end{tabular}

**p $<0.01$ (Note: Section A consists of 10 multiple-choice items; Section B consists of nine two-tier multiple-choice items).

It is imperative to point out that the strength of the difference between the pre-test and post-test mean scores was determined by computing the effect size, Cohen's $d$. Cohen (1988) defines the effect size as being small when $d=0.2$, medium when $d=0.5$ and large when $d=0.8$. The Cohen's $d$ values suggest that the difference between the means was small for the control group while the difference between the means was large for the experimental group. As illustrated in Figure 1 below, the performance of the control group remained largely steady which suggests that traditional instruction was not effective as an intervention to enhance conceptual understanding by dispelling misconceptions. This observation underscores the need for the adoption of appropriate innovative instructional strategies geared towards the inculcation of cognitive and reflective skills. The redundancy of teacher-centred pedagogical approaches has to be viewed in a serious light with a view to sensitise teachers to adopt and implement learner-centred pedagogical approaches which can essentially be used to foster technology-enhanced learning. 
Figure 1. Overall performance of the individual participants in the control group.

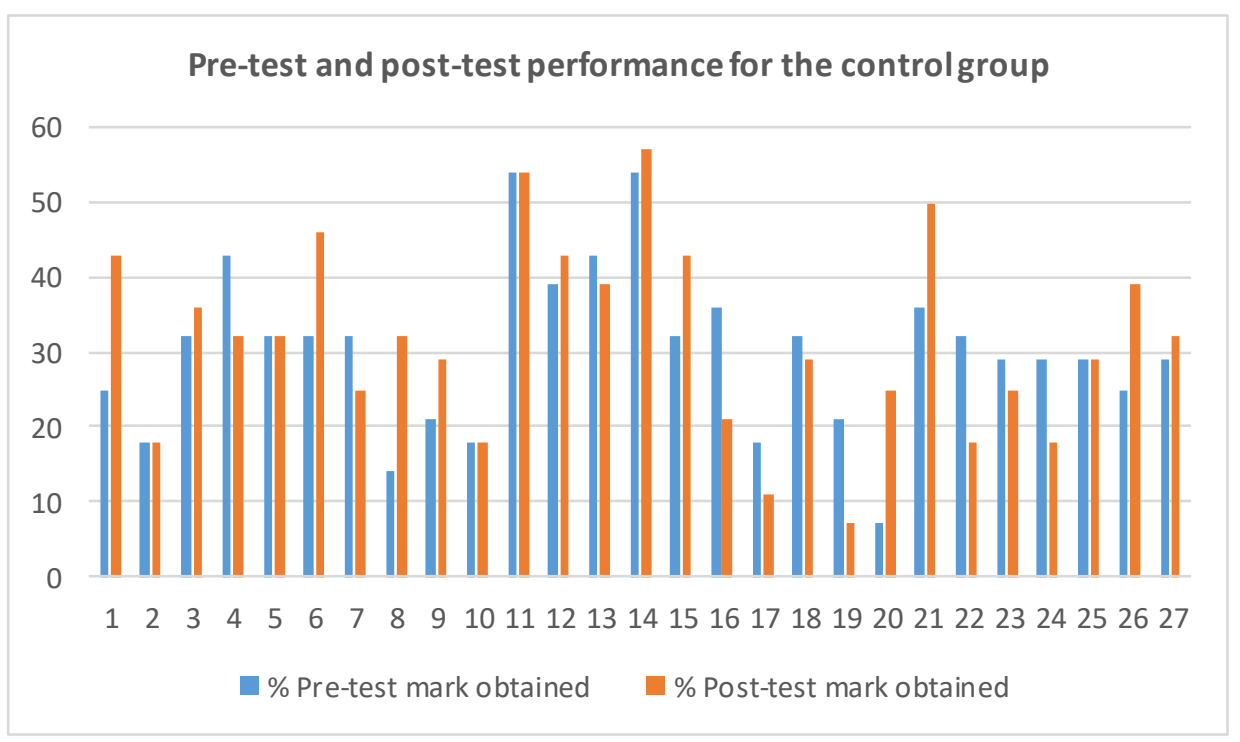

As illustrated in Figure 2 below, the performance of the experimental group improved as a result of the implementation of virtual laboratory simulations as an innovative intervention to address learners' misconceptions. This performance improvement suggests that virtual laboratory simulations can be used as an innovative intervention to enhance understanding of abstract scientific concepts by dispelling misconceptions.

Figure 2. Overall performance of the individual participants in the experimental group.

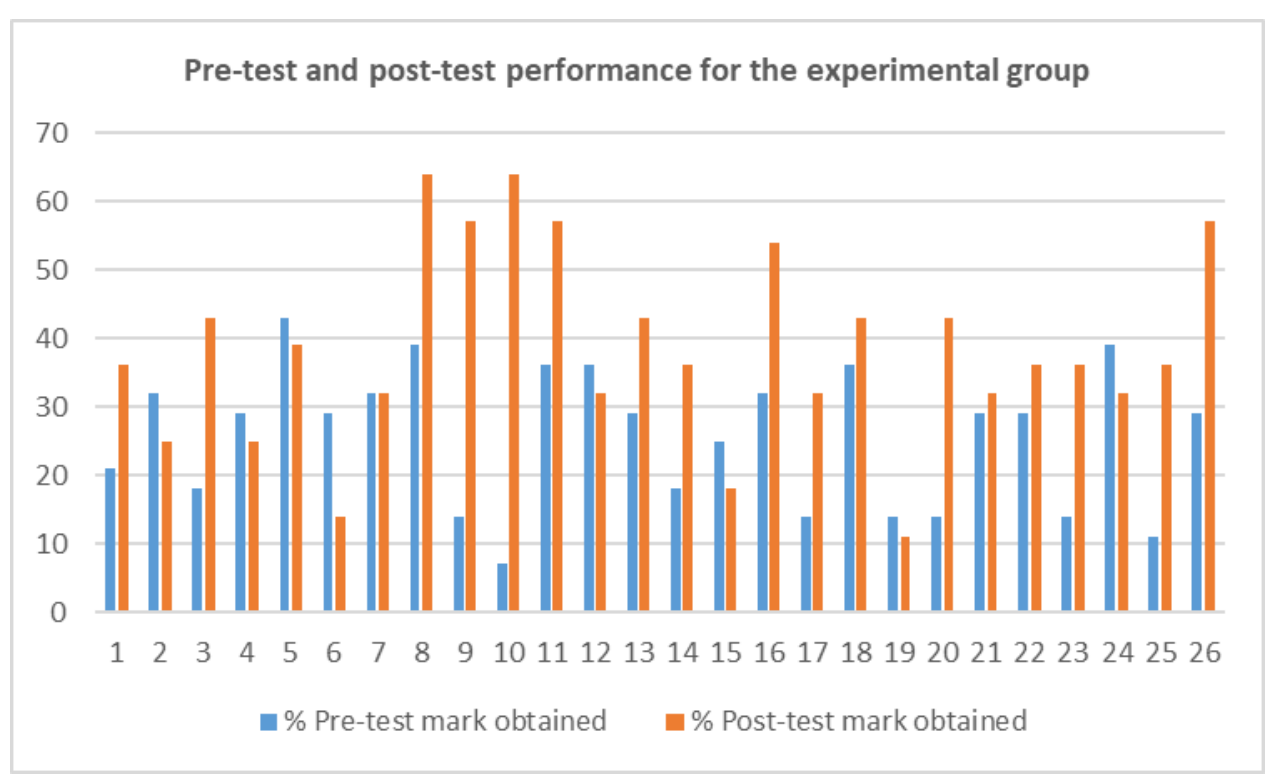

Table 3 below provides the overall post-test and pre-test mean scores for the control group and the experimental group. The results show that the post-test mean score was significantly higher $(\mathrm{M}=38$, $\mathrm{SD}=14)$ than the pre-test mean score $(\mathrm{M}=26, \mathrm{SD}=10)$ for the experimental group. There was no significant difference between the post-test mean score $(\mathrm{M}=32, \mathrm{SD}=13)$ and the pre-test mean score $(\mathrm{M}=30, \mathrm{SD}=11)$ for the control group.

Table 3. Overall post-test and pre-test mean scores for the control group and the experimental group.

\begin{tabular}{lllllc}
\hline & \multicolumn{2}{c}{ Pre-test } & & \multicolumn{2}{c}{ Post-test } \\
\cline { 2 - 3 } & Mean & SD & & Mean & SD \\
\hline Control Group & 30 & 11 & & 32 & 13 \\
Experimental Group & 26 & 10 & & 38 & 14 \\
\hline
\end{tabular}


Table 4 below provides interview schedule and some of the responses provided by the participants. The learners were largely pleased with the efficacy of virtual laboratory simulations and concomitant activities.

Table 4. Excerpts from semi-structured interviews.

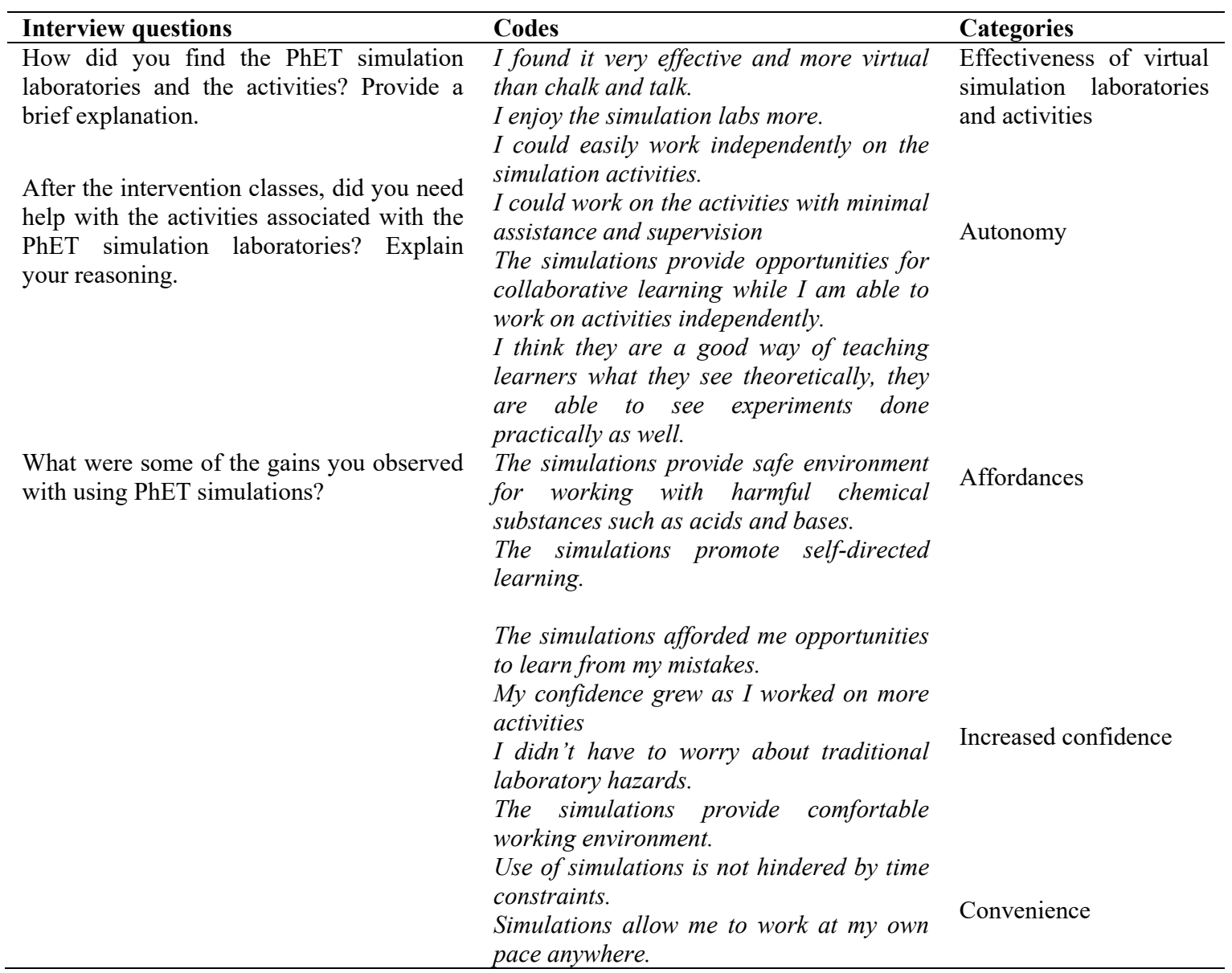

\section{Discussion}

The key findings in this research study pointed to the inadequacy of traditional instruction as a means to enhance meaningful conceptual understanding by dispelling misconceptions. The use of virtual laboratory simulations as an innovative intervention to address misconceptions appears to be a promising pedagogic approach in view of the overall improved performance demonstrated by the participants in the experimental group in particular. The use of virtual laboratory simulations provides learners with meaningful platforms to experiment and manipulate different variables and such opportunities are not provided by the use of traditional and rote memorization learning strategies (Clark, Tanner-Smith \& Killingsworth, 2016; Merchant, Goetz, Cifuentes, Kenney-Kennicutt \& Davis, 2014). Several studies have established that virtual laboratory learning (immersive or non-immersive virtual reality and augmented reality) has positive impact on learners' attitudes and motivation towards science learning in general (e.g. Chua \& Karpudewan, 2017; Hsu, Lin, \& Yang, 2017).

While the participants in this study were largely pleased with the efficacy of virtual laboratory simulations as an innovative intervention to address misconceptions, they cautioned that virtual laboratory simulations cannot supersede traditional laboratories in view of their critical role in the development of science process skills. Arvind and Heard (2010) assert that the use of virtual laboratory simulations serves to simplify complex physics concepts and changes learners' negative perceptions of the physics course in particular. According to Tüysüz (2010), learners who are comfortable with the use of virtual laboratory simulations often show a more positive attitude towards learning chemistry concepts. However, a study conducted by Faour and Ayoubi (2018) on the assessment of grade 10 learners' attitudes towards physics following a virtual laboratory intervention found no significant attitude differences. Additional pedagogic benefits provided by the use of virtual laboratory simulations include provision of meaningful opportunities for self-directed learning and visualization of complex scientific phenomena. 


\section{Conclusion}

The use of virtual laboratory simulations as an innovative intervention to address misconceptions appears to be a promising pedagogic approach as evidenced by the findings in this research study. There is a crucial need for teachers to adopt innovative instructional strategies that are responsive to the critical needs of learners. Sustained commitment to such key endeavours can potentially serve to demystify opportunities associated with the advent of the fourth industrial revolution as a game-changer.

\section{References}

Artdej, R., Ratanaroutai, T., Coll, R. K., \& Thongpanchang, T. (2010). Thai Grade 11 students' alternative conceptions for acid-base chemistry. Research in Science and Technological Education, 28(2), 167-183.

Arvind, V.R. \& Heard, J.W. (2010). Physics by simulation: Teaching circular motion using applets. Latin American Journal of Physics Education, 4(1), 35-39.

Chua, K.H. \& Karpudewan, M. (2017). The role of motivation and perceptions about science laboratory environment on lower secondary students' attitude towards science. Asia-Pacific Forum on Science Learning and Teaching, 18(2), Article 8.

Clark, B. D., Tanner-Smith, E.E. \& Killingsworth, S.S. (2016). Digital games, design, and learning: A systematic review and meta-analysis. Review of Educational Research, 86(1), 79-122.

Cohen J. (1988). Statistical Power Analysis for the Behavioral Sciences. New York, NY: Routledge Academic.

Damanhuri, M.I.B, Treagust, D.F., Won, M \& Chandrasegaran, A.L. (2016). High School Students' Understanding of Acid-Base Concepts: An Ongoing Challenge for Teachers. International Journal of Environmental \& Science Education, 11(1), 9-27.

Denzin, N.K. \& Lincoln, Y.S. (2005). The Sage 'Handbook of Qualitative Research'. Third Edition. Sage Publications: Third Oaks, California.

Faour, M.A. \& Ayoubi, Z. (2018). The effect of using virtual laboratory on grade 10 students' conceptual understanding and their attitudes towards physics. Journal of Education in Science, Environment and Health (JESEH), 4(1), 54-68.

Hsu, Y. S., Lin, Y.H. \& Yang, B. (2017). Impact of augmented reality lessons on students' STEM interest. Research and Practice in Technology Enhanced Learning, 12(2), 1-14. https://phet.colorado.edu/en/simulations.

Johnson, R.B., \& Onwuegbuzie, A.J. (2004). Mixed methods research: A research paradigm whose time has come. Educational Researcher, 33(7), 14-26.

Merchant Z, Goetz, E.T., Cifuentes, L., Kenney-Kennicutt, W. \& Davis, T.J. (2014). Effectiveness of virtual reality-based instruction on students' learning outcomes in K-12 and higher education. Computers \& Education, 70, 29-40.

Reddy, V. (2006). Mathematics and Science Achievement at South African Schools in TIMSS 2003. HSRC Press.

Saldana, J. (2009). The Coding Manual for Qualitative Researchers. London: SAGE Publications.

Tüysüz, C. (2010). The Effect of the Virtual Lab. on Students' Achievement and Attitude in Chemistry. International Online Journal of Educational Sciences, 2(1), 37-53. 